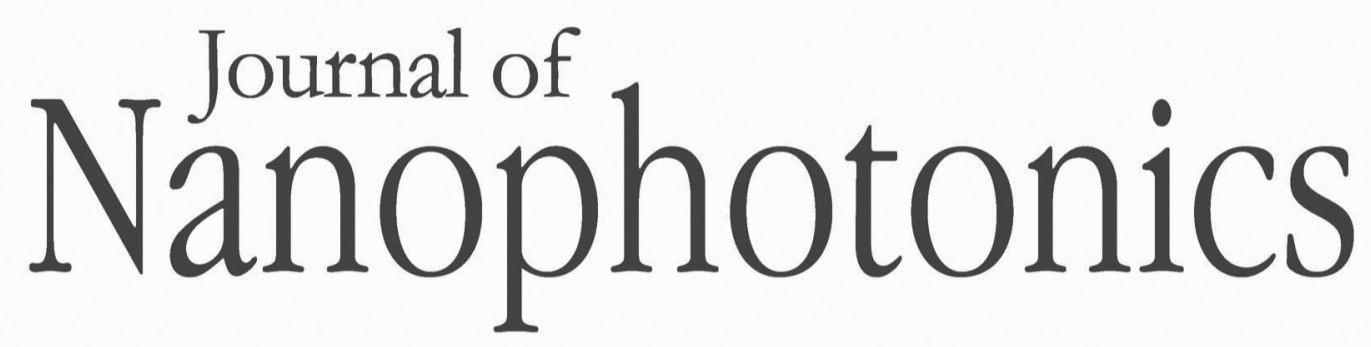

SPIEDigitalLibrary.org/jnp

\title{
Publisher's Note: Synthesis, electromechanical characterization, and applications of graphene nanostructures
}

Traian Dumitrică

Suneel Kodambaka

Sukky Jun

\section{O SPIE}




\title{
Publisher's Note: Synthesis, electromechanical characterization, and applications of graphene nanostructures
}

\author{
Traian Dumitrică, ${ }^{a}$ Suneel Kodambaka, ${ }^{b}$ and Sukky Jun ${ }^{\mathrm{c}}$ \\ ${ }^{a}$ University of Minnesota, Department of Mechanical Engineering, \\ Minneapolis, Minnesota 55455 \\ td@me.umn.edu \\ ${ }^{\mathrm{b}}$ University of California Los Angeles, Department of Materials Science and Engineering, \\ Los Angeles, California 90095 \\ ${ }^{\mathrm{c}}$ University of Wyoming, Department of Mechanical Engineering, Laramie, Wyoming 82071 \\ [DOI: 10.1117/1.JNP.6.060104]
}

This article was originally published in Vol. 6 of the Journal of Nanophotonics on 24 February 2012 in the wrong section of the table of contents and with an incorrect citation identifier (CID) of 019901. The paper was removed and republished online with the correct CID of 064501 on 19 March 2012. This change was made in order for the paper to appear under the correct section heading, "Review Papers."

For more information on the use of CIDs in JNP, see http://spiedigitallibrary.org/jnp/ citation_format.

0091-3286/2012/\$25.00 () 2012 SPIE 